\title{
FUNDAÇÕES E EDUCAÇÃO BÁSICAA: O CASO DA FUNDAÇÃO MUNICIPAL DE EDUCAÇÃO DE NITERÓI-RJ
}

\author{
Luiz Carlos de Almeida Batista Pustiglione $^{1}$
}

\begin{abstract}
RESUMO
O objetivo desse artigo é esboçar uma análise da literatura e legislação disponíveis acerca das fundações públicas e privadas, em especial das ligadas à administração educacional. Para além disto procurou-se delinear a relação entre o tema das fundações como opção privilegiada para imposição de determinado viés sociopolítico na área da educação cotejando-a com a inovação do município de Niterói-RJ que procurou antecipar-se ao que se desenhava na reestruturação/reforma do aparelho de Estado, especialmente nos anos 1990 ao criar uma Fundação Municipal de Educação (FME) para administrar o conjunto de escolas, servidores e contratos da rede municipal de ensino.
\end{abstract}

Palavras-chave: Fundações; Educação; Reforma de Estado

\section{FOUNDATIONS AND BASIC EDUCATION: THE CASE OF THE MUNICIPAL EDUCATION FOUNDATION OF NITERÓI-RJ}

\begin{abstract}
The purpose of this article is to sketch an analysis of available literature and legislation on public and private foundations, especially those linked to educational administration. In addition, we sought to delineate the relationship between the theme of foundations as a privileged option to impose a certain sociopolitical bias in the area of education, matching it with the innovation of the municipality of Niterói-RJ, which sought to anticipate what was being designed in the restructuring / reform of the state apparatus, especially in the 1990s when creating a Municipal Education Foundation (FME) to administer the set of schools, servers and contracts of the municipal education network.
\end{abstract}

Keywords: Foundations; Education; State Reform

\section{INTRODUÇÃO}

A presença das fundações na vida cotidiana das pessoas já é algo tão rotineiro que muitas vezes passam despercebidas as nuances que esse tipo de instituição guarda quando atende ao público ou presta serviços. Na saúde, no esporte, na cultura e na educação há um sem número de fundações públicas municipais, estaduais e federais, bem como de fundações privadas que mantém

\footnotetext{
${ }^{1}$ Mestrado em Educação pelo Programa de Pós Graduação da Universidade Federal do Rio de Janeiro. Técnico em Assuntos Educacionais na UFRJ (cedido para colaboração técnica ao IFC). Rua J, 103 - Jd. Ultramar, Bal. Gaivota/SC. luizlef@yahoo.com.br
} 
escolas, times esportivos, unidades de saúde, pessoal para trabalhar nesses locais, entre outros serviços.

$\mathrm{Na}$ educação essa presença é muito forte no nível superior - tanto público quanto privado - e, em menor número há algumas fundações que são ligadas ao nível básico da educação. Estas, em geral, servem de suporte às secretarias de educação dos municípios ou estados atuando na contratação de pessoal e serviços auxiliares para garantir o funcionamento de suas redes de ensino.

Em Niterói-RJ, por outro lado, há uma presença inóspita: uma Fundação Municipal de Educação, doravante denominada FME, que administra a educação municipal de conjunto, como fosse uma Secretaria Municipal de Educação, que no papel até ainda existe, mas cumpre uma função meramente burocrática e praticamente não possui ligação com a vida cotidiana da rede municipal. Essa experiência contém um pouco de ousadia e experimentalismo da parte dos gestores do período de criação da FME, mas também guarda relações íntimas com as aspirações socioeconômicas e políticas das classes dominantes do país, das quais o prefeito da época era um legítimo representante.

Esse artigo pretende expor de forma aligeirada um panorama da presença das fundações na educação brasileira, em especial na educação pública e de nível básico, mas também confirmar a partir da literatura e dados levantados durante a elaboração da dissertação de mestrado que gerou esse artigo, as hipóteses de vinculação do experimentalismo inovador da gestão municipal de Niterói-RJ com projetos políticos de inspiração neoliberal muito presentes na década de 1990.

Na primeira seção trataremos aspectos relacionados às fundações de maneira geral e, em especial, daquelas vinculadas às finalidades educacionais, tanto da esfera pública como privada. A segunda parte trata do caso específico da cidade de Niterói/RJ que possui uma experiência atípica e praticamente exclusiva na administração da rede pública municipal através de uma fundação pública.

\section{FUNDAÇÕES E EDUCAÇÃO NO BRASIL}


No Brasil, as fundações surgiram legalmente entre o fim do século XIX e o início do século XX, ainda que o primeiro esboço de fundação, seja datado de 1738 , com a Fundação Romão de Matos Duarte, cujo patrono resolveu separar parte de seu patrimônio para formar um fundo de auxílio para as crianças deixadas na "roda" da Santa Casa de Misericórdia no Rio de Janeiro (RAFAEL, 1997). A figura da fundação, reconhecida como tal pela legislação e pela doutrina jurídica, passou a existir no Brasil em 1912, ainda que desde 1903 pudessem ser considerados outros itens legais que dariam conta do tema parcialmente.

Do ponto de vista da legislação e da política, há diferentes momentos em que emergem os debates acerca da validade da administração por meio de fundações, pois, podem existir fundações de diferentes tipos e com diferentes finalidades, mas há um fio comum que independe da legislação vigente do país, estado ou município que as institui: prestar atendimento ao público em serviços que são típicos do Estado ou não exclusivos ao mesmo, no caso de fundação pública. Quando se trata de fundações privadas, o traço que as une do ponto de vista legal é muito mais facilmente identificável que no caso das públicas, mas, excluindo-se posicionamentos ideológicos acríticos, não há uma definição fácil para ambas, em especial, para o caso das fundações públicas.

Além das definições jurídicas e das perspectivas históricas das fundações, outro elemento relevante a ser mencionado se dá sobre os difundidos movimentos mais recentes de adequação do(s) Estado(s) a lógicas de administração baseadas na experiência da esfera privada. Esses movimentos, em geral, são precedidos ou causadores de reformas administrativas ou constitucionais, que representam significativas reformas do aparelho de Estado.

Para o ideário defendido pelo então chefe do Ministério da Administração Federal e Reforma do Estado (MARE) - Luiz Carlos Bresser Pereira - os serviços considerados "não exclusivos" do Estado não precisariam do exercício do poder de Estado, ainda que não necessariamente fossem privados ou privatizados. Nesses casos o melhor regime seria o da "propriedade pública não estatal" (BRESSER PEREIRA, 1998). Dessa forma, haveria a possibilidade de criação de Organizações Sociais (OS's), Organizações Não Governamentais (ONG's), fundações privadas e 
outras organizações da sociedade civil, que suplantassem o papel estatal, não só ao prestar o serviço em si, mas também para elaborar, administrar, executar, enfim, ser responsável pelo conjunto do atendimento referente ao serviço prestado.

Tendo tais ideias como base para a reforma do Estado, as fundações públicas seriam um caminho para se colocar em prática esse ideário. Havia, porém, uma dificuldade legal em fazer com que todas as fundações públicas passassem a ser enquadradas como de direito privado, ou, dito de outro modo, como públicas não estatais. Sendo assim, convive(ra)m sob o mesmo arcabouço legal fundações públicas de diferentes personalidades jurídicas.

Essa pretensão de generalizar às fundações o enquadramento no direito privado não ficou retida nos anos 1990, mas, anos depois, já sob o governo do Partido dos Trabalhadores, em 2007, propôs-se a regulamentação² do artigo 37 da Constituição Federal de 1988, que pode ser vista como uma nova tentativa de regulamentar os serviços públicos de acordo com o modelo público não estatal.

A Fundação Municipal de Educação de Niterói, criada em 1991, assim como muitas outras fundações públicas, foram mantidas como instituições de direito público e, consequentemente, são comparáveis a autarquias, tendo os servidores os mesmos direitos dos servidores públicos, e sendo mantidas as demais regras aplicáveis aos órgãos públicos da administração direta e indireta. No estado de São Paulo, no entanto, floresceram muitas fundações públicas inspiradas nessas pretensões do princípio da década de 1990. Ainda que não sejam de direito privado, possuem em seus quadros servidores que, ainda que sejam concursados, têm seus vínculos empregatícios regidos pela Consolidação das Leis Trabalhistas (CLT). Assim, além das fundações estaduais, órgãos públicos tradicionais daquele estado, como as renomadas universidades estaduais, contratam seus servidores (ou empregados) como se faz na esfera privada, através do regime celetista.

O PL 92/07, ainda não aprovado nas casas legislativas, propõe regulamentar a existência de fundações públicas de direito privado em algumas áreas nas quais ainda não era permitido, dentre as quais a educação. 
As áreas nas quais a presença das fundações de todo tipo são mais significativas, entre o final do século $X X$ e início do $X X I$, são: saúde, assistência social, cultura, educação e pesquisa, religião, turismo. ${ }^{3}$

Quando da criação das primeiras fundações ligadas à educação, havia um movimento para vinculá-las às entidades religiosas e/ou assistenciais. Essas fundações, inclusive, não necessariamente eram ou são vinculadas ao ensino propriamente dito, mas às atividades "periféricas".

Nesse caso, estamos abordando apenas fundações privadas, vinculadas, portanto, ao direito e às instituições de mesmo tipo, ainda que, devido ao vínculo histórico e cultural que há entre Igreja e Estado no Brasil, ou às relações extremamente próximas entre as esferas pública e privada, em muitos momentos pode-se confundir as fronteiras e consequentemente o caráter ou personalidade jurídica de uma ou outra fundação.

Após esse movimento inicial, que remonta ao início do século passado, as fundações que surgiram vinculadas à educação passaram a ser instituídas também pelo poder público, e há uma fonte inesgotável de exemplos, principalmente entre as universidades públicas. Em muitos estados, são fundações que administram uma ou mais instituições de ensino superior, criadas sob diferentes personalidades jurídicas e por governos de diversas orientações políticas. Há alguns exemplos possíveis de fundações que administram universidades públicas e gratuitas, mas também universidades privadas. No caso do Estado de Santa Catarina, podemos mencionar a Universidade do Estado de Santa Catarina (UDESC) e a Associação Catarinense de Fundações Educacionais (ACAFE) respectivamente.

Além do caso das instituições estaduais, municipais e privadas, há um bom número de universidades federais que são fundações em sua origem e a maioria delas ainda se mantém assim até a segunda década deste século, como é o caso da (Fundação) Universidade Federal de São Carlos em São Paulo, da (Fundação) Universidade Federal de Rio Grande (RS), da (Fundação) Universidade Federal do

\footnotetext{
3 Em 2010, havia 290,7 mil Fundações Privadas e Associações sem Fins Lucrativos (Fasfil) no Brasil, voltadas, predominantemente, à religião $(28,5 \%)$, associações patronais e profissionais $(15,5 \%) \mathrm{e}$ ao desenvolvimento e defesa de direitos $(14,6 \%)$. As áreas de saúde, educação, pesquisa e assistência social (políticas governamentais) totalizavam 54,1 mil entidades (18,6\%). Disponível em: <http://www.ibge.gov.br/home/estatistica/economia/fasfil/2010/default.shtm>.
} 
Mato Grosso, entre outras. Além dessas, que foram criadas em grande número no período dos presidentes militares, há a Fundação Universidade Federal do Tocantins, criada no Governo Lula da Silva e a Universidade de Brasília idealizada e criada antes do golpe militar, tendo sido, portanto, a primeira universidade fundação do país.

Como a legislação sobre as fundações e eventualmente os contextos são diversos quando tratamos de esfera pública ou privada, exemplificaremos a seguir as diferenças e aproximações entre ambos os tipos de fundações, de forma separada, sem ainda conferir mais de perto o ordenamento jurídico, mas sim as vinculações às quais elas estão submetidas.

$\mathrm{Na}$ educação privada de todos os níveis, o mais comum são as fundações mantenedoras de uma ou mais escolas, faculdades, centros de ensino superior ou instituições que sirvam às finalidades destas.

Fundações privadas podem ser instituídas a partir de instrumento jurídico específico registrado em cartório e não necessitam de autorização/mediação do poder público para funcionarem, basta, como veremos melhor adiante, que seja dotada de patrimônio próprio e alguns outros itens a serem verificados em sua constituição inicial, que pode dar-se tanto por indivíduo ou coletivo de indivíduos em vida, como através de testamento (post mortem). A função social (pública) é, no entanto, determinada por aprovação do poder legislativo ao qual está ligada a fundação (se federal, câmara dos deputados/senado, se estadual, assembleia legislativa e se municipal, câmara dos vereadores).

Alguns exemplos conhecidos de fundações mantenedoras são a Fundação dos Rotarianos de São Paulo, que mantém o tradicional Colégio Rio Branco e outras cinco instituições dedicadas ao ensino, pesquisa e assistência social; a Fundação São Paulo, que mantém a renomada Pontifícia Universidade Católica de São Paulo (PUC-SP), cada qual com suas especificidades, mas mantendo suas atuações centradas na educação, pesquisa e assistência social, baseadas na mesma legislação.

Além das mantenedoras, há outros tipos de fundação que atuam sobre o ensino privado, como, por exemplo, a Fundação Getúlio Vargas ou a Fundação 
Cesgranrio, que realizam serviços vinculados à educação de forma geral e não só ao ensino propriamente dito. Essas fundações realizam pesquisas encomendadas, exames vestibulares ou semelhantes, concursos públicos, processos seletivos públicos, entre outras atividades.

Na educação básica pública, há um número pouco significativo de fundações envolvidas na administração educacional e um número ainda menor quando procuramos fundações que administram o conjunto da educação de uma cidade ou Estado. As poucas que podem ser encontradas, em geral, existem em função da contratação de pessoal para ser cedido às escolas e não, como é o caso na cidade de Niterói, para administrar a rede pública do município como um todo. Em Contagem (MG), por exemplo, há a Fundação de Ensino de Contagem (FUNEC), que realiza as contratações de pessoal para atuar na rede municipal de lá, mas a administração da educação municipal permanece vinculada ao órgão comum para isso, a Secretaria Municipal de Educação.

Há também um número razoável de fundações que, por intermédio das leis das Organizações Sociais e Organizações da Sociedade Civil de Interesse Público, atuam na educação básica a partir de contratos estabelecidos com secretarias para implementação de programas ou projetos, para consultoria, aquisição de materiais didático e paradidáticos, serviços terceirizáveis etc. São os casos de Fundações como o Instituto Ayrton Senna, Fundação Lemann, Itaú Social, entre outras.

Os processos de descentralização de serviços e da administração pública ocorreram em diferentes períodos e ainda ocorrem. Grande exemplo disso é possível ser encontrado na área da educação pública. É importante notarmos que anteriormente às atuais legislações, o município passou por diversas fases em que teve maior ou menor importância enquanto ente público responsável pela oferta de serviços públicos como educação e saúde, principalmente.

Com o advento da Constituição de 1988 e dos debates/implementação prática da nova LDBN os municípios voltam a ter um peso considerável e até mesmo equiparável ao dos Estados e da própria União, ainda que, em termos de formas de financiamento, dada a disparidade de possibilidades financeiras dos diferentes entes, essa questão só fosse ter uma "solução" na área educacional com a 

1997. Esse não é um elemento menor nas/para as discussões que estão sendo levantadas neste artigo, pois o fortalecimento dos municípios está diretamente vinculado ao processo de aproximação entre Estado e sociedade civil e, por consequência, à lógica predominante na década de 1990, que deu base à reforma do Estado.

Havia uma contrariedade grande em determinados setores sobre entregar responsabilidades aos municípios, que tinham - muitos ainda têm - arrecadações limitadas e passariam a ter que administrar demandas enormes, o que poderia facilitar um processo de privatização desses serviços.

No caso das Instituições Federais de Ensino Superior (IFES), Sguissardi e Silva Jr. (1998) citaram em seu livro um passo a passo elaborado pelo MARE para a transformação de universidades autárquicas em Organizações Sociais, fundações ou, utilizando-se das palavras encontradas nos documentos daquele ministério, de publicização dos serviços e estabelecimento de contratos de gestão entre essas e o Estado.

Há também um número considerável de fundações municipais que na verdade são faculdades ou centros universitários criados pelo poder executivo e/ou legislativo das cidades, mas que se assemelham às instituições privadas de mesmo fim. Em Piracicaba (SP), por exemplo, há a Fundação Municipal de Ensino de Piracicaba que na realidade é uma faculdade municipal, na qual os alunos pagam mensalidade, os professores têm seus contratos regidos pela CLT, entre diversos outros exemplos que poderiam ser citados e enquadram-se entre o que fora idealizado como público não estatal.

No caso dos municípios, o que certamente mais pesaria sobre os orçamentos - dos mais apertados aos mais largos - seriam as áreas da saúde e da educação. Nesse sentido, muitos municípios optaram por administrar esses setores por meio de fundações municipais. Niterói, por exemplo, criou as fundações de cultura, de saúde e de educação. 
A disputa entre posições centralizadores e descentralizadoras não ocorre há pouco tempo, ao contrário. Como já foi escrito antes aqui, ela está presente praticamente desde o primeiro debate constitucional e nas duas LDB's.

No que diz respeito à prática política e legislação vigente, a maior parte dos autores citados nesta dissertação apontam um movimento pendular entre centralização e descentralização, que teria cessado com a Constituição Federal de 1988, definitivamente um marco descentralizador, que não teria precedentes e poderia ser considerada como "definitiva" sobre o tema.

Foi a partir da reforma da aparelhagem estatal de 1995, no entanto, que se tornou mais nítido o surgimento de ações estatais objetivando uma alteração no aparato regulatório da relação entre Estado e sociedade civil (ALGEBAILE, 2005).

Há, no entanto, diversas nuances que podem se desprender dessa díade, dentre as quais as relativas às maiores possibilidades de privatização e favorecimentos às empresas privadas ou mesmo ao patrimonialismo tão criticado pelos descentralizadores que, concordando com Bresser Pereira, imaginavam que poderia ser eliminado ou no mínimo diminuído.

O conjunto desses mecanismos regulatórios criados a partir de 1995 tem
como objetivo, explícito ou implícito, regular a relação entre Estado e
sociedade civil, sedimentando uma nova sociabilidade, um novo modelo de
ações sociopolíticas nesses anos de neoliberalismo da Terceira Via. Nesse
sentido, convém investigar os mecanismos que o Estado tem utilizado para
incentivar essa nova sociabilidade, seja por intermédio da elaboração de um
"novo marco legal", seja pelo estímulo à criação e ampliação de organismos
não-estatais, por meio de facilitação de financiamento e normas
autorregulatórias, ou ainda pela alteração da legislação mais ampla. Tais
iniciativas são implementadas concomitantemente; assim, o Estado
educador vai redefinindo de modo sutil suas "regras", de modo a conduzir a
construção de um consenso em torno de uma "nova cultura", que tem por
objetivo sedimentar a hegemonia burguesa sob novos contornos.
(ALGEBAlLE, in NEVES, 2005)

Ainda que haja alguns aspectos positivos no atual processo de municipalização, esse tom descentralizador positivo que se tentou criar, parece ter mais ligações com as intenções de ampliar a participação do setor privado (ou público não-estatal) na educação para além da participação anterior que já havia (FREITAS, 2012). No período de "ingresso" do Brasil no neoliberalismo da Terceira Via, reforma de Estado significou transferir para o setor privado as atividades que podem ser controladas pelo mercado, o que justificaria a generalização dos 
processos de privatização de empresas estatais. Mas há outro processo que merece ser salientado por não ser tão claro: a descentralização para o setor público nãoestatal da execução de serviços que não envolvem o exercício de poder de Estado, mas devem ser subsidiados pelo Estado, como é o caso da educação, saúde, cultura e pesquisa científica (BRASIL, 1995).

\section{O CENÁRIO POLÍTICO E EDUCACIONAL NITEROIENSE: A FUNDAÇÃO MUNICIPAL DE EDUCAÇÃO}

O capital político e a aura de "pai" da cidade do prefeito Jorge Roberto da Silveira à época da criação da FME permitiram que lançasse mão de várias iniciativas - algumas que podem ser consideradas negativas enquanto outras, positivas - inéditas ou experimentais, como é o caso da própria.

Foi, porém, a particularidade marcante na área educacional do município que interessou esta essa pesquisa, qual seja, o fato de a administração de sua pequeníssima rede ter sido delegada, em 1991, à Fundação Municipal de Educação, entidade que se "sobrepõe" cotidiana e administrativamente à Secretaria Municipal de Educação, que, por sua vez, continua existindo, porém com quase nenhum poder sobre a rede municipal de ensino e com uma vinculação de caráter pouco claro com a anterior.

Uma leitura atual sobre a educação no Brasil traz uma série de elementos que eventualmente podem merecer algum destaque a partir dessa situação específica do município de Niterói. Há uma aproximação do privado e do público evidente, principalmente a partir dos anos 90, como uma possível consequência do processo de municipalização e que fez "estourar" uma série de políticas e iniciativas por parte dos gestores e administradores municipais. Com relevância para a presente pesquisa, destacaria as Parcerias Público-Privadas e a terceirização, porém sem ignorar a política de proliferação de projetos (geralmente vendidos por organizações privadas) que, de acordo com entrevistas com os gestores do Programa Educação Integral de Niterói (PUSTIGLIONE, 2012) e pela percepção comum às unidades escolares, foi aplicada recentemente nas escolas municipais de forma indiscriminada. 
Esse tipo de relação entre a esfera pública, no caso de Niterói, em especial, a Fundação Municipal de Educação e entidades privadas ou do terceiro setor, avançou desde a década de 1990, na esteira do Plano Diretor da Reforma do Aparelho do Estado (BRASIL, 1995).

Peroni, Oliveira e Fernandes (2009) apontaram que, sob o contexto da implementação desse plano diretor, que visava reformar a estrutura estatal e previa as bases pelos quais o Estado deveria funcionar - privatização, descentralização e publicização - acabou por desatar outra série de reformas e alterações no cenário político-institucional também nas esferas municipal e estadual. Nesse período, há também uma interpretação constituída de que a crise que desde a década de 1970 ronda permanentemente a economia mundial é uma crise "do" Estado e por consequência gera a necessidade deste modificar-se, reformar-se, a depender do ponto de vista assumido.

Ressalte-se que o período citado da discussão e implementação da reforma de Estado coincide com o período de criação da Fundação Municipal de Educação em Niterói, que surge no intuito de "modernizar" e tornar mais "eficaz" e "eficiente" a administração da coisa pública. Essa mudança de personalidade jurídica do órgão responsável pelo maior orçamento do município não é um dado irrelevante, ao contrário, ao criar-se uma fundação, abrem-se muitas possibilidades de superação de trâmites burocráticos que seriam "empecilhos" ao bom andamento e desenvolvimento da educação. Esse recurso não foi adotado apenas na cidade de Niterói ou na área da Educação, em muitos casos estende-se essa situação à cultura, ao esporte e principalmente à saúde, mas também nas universidades públicas e privadas as fundações são um "recurso" bastante utilizado.

A esse contexto, em que se buscava uma modernização da administração do Estado e dos serviços ofertados e se assumia o privado como o modelo "ideal", somava-se o já citado processo de municipalização do ensino fundamental no Brasil. Assim, muitas prefeituras buscaram parcerias, alternativas no terceiro setor, para execução de políticas educacionais, com intuito de superar os problemas educacionais e principalmente modernizar a gestão escolar (PERONI; OLIVEIRA; FERNANDES, 2009). 


\section{RESULTADOS}

Ressaltamos de início que, do ponto de vista da análise documental, essa pesquisa sofreu de um mal que muitas outras sofrem: a falta de arquivos organizados, tanto da parte do poder público, como das entidades sindicais e/ou de organização da sociedade civil. Sendo assim, a essência das respostas e indícios que conseguimos vieram majoritariamente das entrevistas semiestruturadas realizadas com as pessoas que estavam envolvidas diretamente com a criação e desenvolvimento da Fundação Pública Municipal de Niterói. Ouvimos quem esteve à frente da gestão da fundação, da secretaria (dos dois ao mesmo tempo ou em períodos distintos), quem atuava na Câmara Municipal, no Sindicato Estadual dos Profissionais da Educação ou em atividade nas escolas dessa rede municipal.

Dito isso, podemos nos lançar a algumas conclusões ou, minimamente, considerações mais criteriosas sobre o objeto de estudo posto.

Niterói é uma cidade importante no contexto fluminense, tendo já sido a capital do antigo Estado do Rio de Janeiro até 1975 - ano da fusão deste com o Estado da Guanabara, quando a capital foi transferida para a cidade do Rio de Janeiro. Essa importância (e o antigo status de capital), serviu para que a cidade fosse muito bem assistida de equipamentos públicos construídos e mantidos pelo governo estadual, dentre os quais destaca-se uma importante rede estadual de ensino, que abriga no segundo segmento do ensino fundamental o triplo do número de matrículas da rede municipal e se põe em pé de igualdade com a grande rede privada que há nessa cidade.

Para o interesse desta pesquisa, esse era um dado dos mais relevantes, uma vez que é notório que o crescimento da rede municipal não acompanhou o ritmo do crescimento das redes municipais de outras cidades, de porte semelhante ou não, pois, principalmente após o advento do Fundo de Desenvolvimento do Ensino Fundamental (FUNDEF), diversas prefeituras passaram a assumir matrículas das redes públicas (estaduais) e construir novas unidades educacionais, o que não ocorreu em Niterói na mesma escala. 
Dessa maneira a FME/prefeitura ficou em posição "confortável" no tema da expansão da rede municipal, já que ao mesmo tempo há uma enorme rede privada e também uma grande rede estadual, resquício ainda do período no qual Niterói foi capital. É interessante notar, ainda nesse meandro, que todas as transferências da rede estadual para a prefeitura de Niterói partiram de iniciativas do governo do Estado ou da Assembleia Legislativa do Estado do Rio de Janeiro (ALERJ), com exceção da tentativa de municipalizar os CIEP's feita pela então secretária de educação e presidente da FME Lia Faria, rejeitada por Jorge Roberto da Silveira e pelo secretário de Fazenda à época, e de algumas escolas estaduais incorporadas ao final do mandato do ex-prefeito Godofredo Pinto.

Esses são elementos que, para além de explicar a pequena expansão da rede pública municipal e da importância de Niterói no contexto político estadual, também nos dão indícios de que alguns dados positivos conquistados por essa rede também se devem ao fato de ser uma rede pequena, na qual as ações podem ser mais precisas do que quando se tem a necessidade de atender mais de uma centena de escolas, como ocorre em municípios do mesmo porte de Niterói. É importante relembrar que, apesar de alguns aspectos positivos da rede terem sido construídos ao longo desses anos de existência da FME, se focarmos nosso olhar sobre o índice oficial da avaliação da educação básica, o IDEB, Niterói está em uma colocação ruim, 580, inferior a muitas cidades de IDH e arrecadação financeira menores.

Alguns desses dados, aliás, não necessariamente são positivos por responsabilidade direta da gestão educacional da cidade, pois como vimos, a rede privada é imensa e maior que a rede pública, se somarmos a educação infantil e o ensino fundamental ofertada pelas três esferas governamentais (municipal, estadual e federal). Refiro-me ao ótimo Índice de Desenvolvimento Humano (IDH) da cidade, uma vez que mesmo tendo caído no período da década de 1990 até os dias de hoje, ainda se mantém "muito alto" (uma das 44 de todo o país dessa categoria), sendo o $1^{0}$ no Estado e 70 no país. A arrecadação municipal também é relevante, sendo a $5^{a}$ cidade do Estado nesse quesito.

A Fundação Municipal de Educação certamente pode ser incluída no rol de 
inovações que o ex-prefeito trouxe à cidade no início da década de 1990, tal como mostramos. Havia uma atmosfera favorável ao experimentalismo e, no caso da educação, a opção foi criar a FME, pois, ainda que isso acabasse por criar uma aresta que em parte se colocaria contra essa proposta, parecia haver a necessidade de que a administração de JRS deixasse marcas - o que foi citado pelas professoras Lia Faria e Maria Inês de Oliveira em entrevistas concedidas para esta pesquisa.

Esse é um indício importante para uma das questões que nos colocamos sobre os argumentos decisivos para se criar uma fundação em vez de manter o esquema tradicional com a SME, pois faz-nos parecer que, se os critérios centrais para essa tomada de decisão foram de ordem jurídico-administrativa e menos políticos, nem por isso os impactos nesse campo são menos relevantes. 0 questionamento à criação da fundação foi principalmente de ordem política. Julgavase ter a fundação (qualquer fundação) um caráter "privatizante" a priori. Dessa forma, ou JRS não tinha a noção completa do significado de sua ação naquela conjuntura e os reflexos que ela geraria, ou estava antecipando (em alguns anos) uma tendência que posteriormente se difundiu, de medidas heterodoxas do ponto de vista dos partidos localizados mais à esquerda do espectro ideológico.

Dizemos isso, pois, entre os que criticavam, havia um temor de que a administração pela fundação possibilitaria uma relação mais "íntima" com o setor privado ou um distanciamento entre a gestão pública da educação e os profissionais, estudantes e famílias que atuavam ou eram atendidos pela rede municipal. Como nos indicou Arosa (2011), havia, entre a declaração e a execução do modelo de gestão praticado, um conflito entre práticas e concepções de inspiração burocrática e de certo "gerencialismo" que aparece de modo mitigado em meio a um discurso democratizante.

Como pudemos também verificar, houve uma resistência muito grande e organizada contra a criação da FME, tanto por parte de personalidades intelectuais e políticas, como por parte do movimento organizado dos trabalhadores em educação da rede municipal e, ao enxergar alguns desses elementos citados anteriormente, um setor desses profissionais do quadro da SME optou por resistir à mudança para a FME, mesmo após a aceitação maciça do restante da categoria. Ainda que tenham 
sido inicialmente poucos servidores e que com o passar dos anos a aposentadoria ou saída da rede de alguns esse número tenha diminuído ainda mais, o fato político (e jurídico) causado por essa resistência gera reflexos até o momento em que essa pesquisa foi realizada e fazia com que a SME ainda tivesse um quadro de profissionais que atuavam nas escolas da rede e não apenas nas funções administrativas e cargos comissionados como se planejava inicialmente.

Realmente, no período inicial da fundação, era possível identificar uma série de ações que indicavam esse sentido posto pelos críticos, afinal os servidores nela lotados passaram a ser parte de outro quadro que não o da prefeitura municipal, com salários diferenciados destes (ainda que no primeiro momento isso tenha sido positivo, pois passaram a ganhar melhor que os demais servidores municipais), a fundação poderia - e ainda pode - licitar independentemente, bem como administrar sua própria verba sob responsabilidade exclusiva de seu presidente.

Esse ímpeto da parte da gestão municipal em modernizar a administração pública sob os preceitos "gerencialistas", mirando na Reforma Administrativa que se avizinhava em nível federal e já começava também em outros estados e municípios, em lugar de ganhar fôlego com o passar dos anos, foi perdendo parte do sentido que tinha inicialmente. Isso se deu por uma série de razões, entre as quais, citamos: a não efetivação de alguns preceitos legais que figuravam nos principais projetos de reforma do aparelho estatal, mudanças feitas sobre alguns dos preceitos que foram regulamentados de maneira diversa ao que se acreditava que ocorreria e ações judiciais que podem ser consideradas consequências dos motivos anteriores, mas na prática, garantiram na área trabalhista que a diferenciação entre o quadro da SME e da FME deixasse de ser possível.

Independente da condição de "pioneira" da FME e das disputas que gerou, o que acabou ocorrendo em sua prática cotidiana não foi diferente do que ocorreu em outras cidades que mantiveram a estrutura administrativa convencional da educação municipal. Em inúmeras cidades brasileiras a cessão de responsabilidades educacionais para agentes do setor privado, por meio de compra de pacotes e materiais didáticos e até mesmo de serviços de gestão, passou a se dar independentemente do formato da estrutura governamental. 
É preciso destacar ainda uma peculiaridade do perfil de uma parte dos gestores da cidade e da educação que, justamente por sua extração partidária e/ou ideológica, em especial os que estiveram à frente de SME e FME nos primeiros tempos, por mais que tenham aderido à sua criação, não permitiram que os conteúdos e possibilidades mais tipicamente "gerencialistas" ou privatizantes fossem priorizados, ao contrário dos que estiveram à frente do cargo nos dois últimos mandatos de Jorge Roberto da Silveira. Grosso modo, significa afirmar que no início do período de administração fundacional, pessoas identificadas com a educação pública foram convocados à tarefa de administrá-la e com o passar dos mandatos, foram assumindo a função pessoas menos identificadas com a defesa da educação pública e/ou originados nela, fosse como professores(as) ou em outras funções pedagógicas e administrativas em escolas ou universidades. $O$ experimentalismo nessa direção foi muito baixo se comparado, por exemplo, com prefeituras do estado de São Paulo já citadas anteriormente.

Algumas medidas da FME ao longo desses poucos mais de vinte anos de existência, ao contrário de serem medidas "gerencialistas" ou excludentes, acabaram por tornarem-se referências democráticas, como no caso das eleições diretas para a direção das escolas municipais, a implantação da avaliação continuada (embora questionada) e dos ciclos. Outra medida favorável à rede municipal se dá no atendimento de alunos portadores de necessidade educacionais especiais (PNEE), área na qual não só as entrevistas afirmaram o vanguardismo do trabalho como também os bons índices e a procura de famílias que moram em outros municípios e chegam a se mudar para a cidade em busca dessa qualidade no atendimento público.

\section{CONSIDERAÇÕES FINAIS}

Sendo assim, há duas reflexões importantes que ao final deste trabalho queremos reter. Uma delas relaciona-se com essa contradição (ou disputa) entre os que assumiram os cargos de gestão da educação municipal e a estrutura que se intencionou criar com a FME, pois, se é verdade que esse grupo de gestores não impediu a criação da FME com todo seu perfil, em tese, "gerencialista" e privatizante, 
é verdade também que Niterói nunca tornou-se um exemplo nacional de modelo neoliberal de como administrar uma rede municipal de educação. O que houve foi uma acomodação no que diz respeito à estrutura, afinal como já vimos, nem as entidades e setores que se opunham à criação da fundação continuaram uma movimentação pelo seu fim e/ou o retorno da administração da educação à SME.

A outra reflexão parte de uma constatação que ao longo de toda a dissertação apareceu diversas vezes: os tamanhos da rede privada (enorme) e da rede municipal (muito pequena). A expansão da segunda, que apesar de estar incluída entre os objetivos da FME no decreto que a cria e no Regimento Interno, foi muito pequena conforme os números demonstraram.

Apresentamos também algumas hipóteses para o não crescimento da rede municipal e, nessas considerações finais, queremos destacar a questão do tamanho da rede privada. Conforme já mencionado, até para os padrões do estado do Rio de Janeiro, que tem no geral uma rede privada significativa, Niterói se destaca pelo grande número de escolas privadas quando comparado a outros municípios com número total aproximado de escolas de ensino fundamental, sejam municípios vizinhos, bem como na comparação com os demais municípios fluminenses. Essa distorção da dimensão das redes pública e privada em Niterói fica ainda mais evidente quando cotejamos os seus números com a média nacional de atendimento por rede.

Portanto, nosso estudo mostrou que as administrações municipais em Niterói, conseguiram dar conta dos problemas cotidianos da rede escolar. Implementaram algumas inovações importantes, outras questionáveis e outras que fizeram a FME servir ao jogo político da distribuição de cargos em comissão entre os partidos aliados. Mas, acima de tudo, essas administrações nunca pautaram a sério e com a devida prioridade a questão da expansão da rede municipal de ensino, permitindo assim (por inação) o surgimento de escolas privadas de qualidade questionável que atendem setores que não podem pagar pelas escolas tradicionais daquela cidade, mas que também não conseguem encontrar vagas próximas às suas casas na rede municipal, que não cresce, ou na estadual que diminui. É então urgente que as reflexões e ações daqueles que atuam na/sobre a rede municipal de ensino daquela 
cidade caminhem no sentido de pensar soluções para o problema da distribuição e tamanho das redes públicas, em especial da rede pública municipal de ensino fundamental.

\section{REFERÊNCIAS BIBLIOGRÁFICAS}

ALGEBAILE, E. As ações da sociedade civil e do Estado diante da pobreza. In: VALLA, V.; STOTZ, E.; ALGEBAILE, E. (Org.). Para compreender a pobreza no Brasil. Rio de Janeiro: Escola Nacional de Saúde Pública Sérgio Arouca-ENSPFiocruz / Contraponto, 2005, v. 1, p. 73-99.

ALGEBAILE, M. E. B. Mecanismos regulatórios como elementos constitutivos da nova pedagogia da hegemonia. In: NEVES, L. M.W. (org.). A nova pedagogia da hegemonia: estratégias do capital para educar o consenso. São Paulo: Xamã, 2005. p. 193-206

AROSA, A. C. As políticas educacionais de Niterói entre 2002 e 2008. In: XXV Simpósio Brasileiro, II Congresso Íbero-Americano de Política e Administração da Educação - Jubileu de Ouro da ANPAE (1961-2011), 2011, São Paulo. Anais... São Paulo: Biblioteca ANPAE, 2011, p. 1-13.

BRASIL. MARE. Câmara da Reforma do Estado. Plano Diretor da Reforma do Aparelho de Estado. Brasília, 1995.

BRESSER-PEREIRA, L. C. A Reforma do Estado nos anos 90: Lógica e Mecanismos de Controle. Lua Nova. Revista de Cultura e Política, São Paulo, v. 45, p. 49-95, 1998.

FREITAS, L. C. de. Os reformadores empresariais da educação: da desmoralização do magistério à destruição do sistema público de educação. Educação \& Sociedade (Impresso), Campinas, v. 33, p. 379-404, 2012.

PERONI, V. M. V.; OLIVEIRA, R. T. C.; FERNANDES, M. D. E. Estado e terceiro setor: as novas regulações entre o público e o privado na gestão da educação básica brasileira. Educação \& Sociedade (Impresso), v. 30, p. 761-778, 2009.

PUSTIGLIONE, L. Políticas públicas municipais de ampliação da jornada escolar: um estudo sobre o Programa Educação Integral da Prefeitura Municipal de Niterói. Monografia de Especialização. Universidade Federal do Rio de Janeiro, Rio de Janeiro, 2012.

RAFAEL, E. J. Fundações e direito. São Paulo: Companhia Melhoramentos, 1997.

SGUISSARDI, V.; SILVA Jr., J. R. Novas faces da educação superior no Brasil: reformas do Estado e mudanças na produção. São Paulo: Cortez, 2001. 279 p.

SGUISSARDI, V. Universidade, fundação e autoritarismo: o caso da UFSCAR. São Paulo: 
Recebido em setembro 2018 Aprovado em outubro 2018 